\title{
Patients with atherosclerotic renovascular disease presenting to a renal unit: an audit of outcome
}

\author{
J.E. Scoble, P. Sweny' ${ }^{1}$, G. Stansby' and G. Hamilton ${ }^{1}$ \\ King's College Hospital, London SE5 and ${ }^{1}$ Royal Free Hospital, London NW3, UK
}

\begin{abstract}
Summary: During a 6 year period 60 patients with atherosclerotic renovascular disease were followed by a single renal unit. Angiotensin converting enzyme inhibitors were being taken by $22 \%$ of patients at the time of diagnosis of the atherosclerotic renovascular disease. Intervention to revascularize renal tissue by surgery or angioplasty was performed in 32 patients. Revascularization was not undertaken because of unilateral disease, patient preference, poor operative risk or renal size. The mean age for the nonintervention group was 66.9 years and 63.4 years for the intervention group. Peripheral vascular. disease was common in both groups ( $96 \%$ nonintervention group versus $86 \%$ intervention group). There was a statistically significant difference in improvement in renal function in the intervention group $(34.4 \%$ versus $10.7 \%)$ in spite of more patients being dialysis dependent in the intervention group $(28.1 \%$ versus $14.3 \%)$. There was no statistically significant difference in survival between the two groups although the trend was for better survival in the group with intervention.

Patients presenting with impaired renal function and atherosclerotic renovascular disease can have useful improvement in renal function with revascularization without any detriment to survival.
\end{abstract}

\section{Introduction}

Atherosclerosis as a cause of renovascular disease (ARD) leading to acute and chronic renal failure is well established. Recent estimates have suggested that in fact it is a common cause of both. ${ }^{1-4}$ Once ARD is present then progressive deterioration will occur. ${ }^{5}$ Early case reports followed by large series of selected patients have suggested that intervention by either angioplasty or surgery can improve renal function..$^{6-13}$ Patients with ARD have widespread atheroma affecting many other organs and are at high risk from any intervention due to these. Advances in dialysis techniques now mean that many of these patients can be dialysed and renal failure no longer leads to death. A physician seeing a patient with ARD and renal failure will need to balance the risks against the possible benefits of any intervention. A number of trials are ongoing to compare intervention and nonintervention in patients with atherosclerotic renovascular disease but these are only looking at patients with modestly impaired renal failure (plasma creatinine less than $200-300 \mu \mathrm{mol} / \mathrm{l})$. It is difficult to perform a randomized control led trial of intervention in patients with severely impaired renal function but it is also important that intervention does produce positive effects.

Correspondence: J.E. Scoble, M.A., M.D., M.R.C.P., Renal Administration, Dulwich Hospital, East Dulwich Grove, London SE22 8PT, UK.

Accepted: 14 December 1992
This paper seeks to analyse the outcome of all patients identified as having ARD at a single renal unit. Intervention, both angioplasty and surgery, was performed in over half the patients and the results are analysed. It is important that units in which frequent intervention is practised can demonstrate the worth of this approach. From this audit of clinical practice it may be possible for other physicians to judge the merit of intervention.

\section{Methods}

All patients with a clinical suspicion of ARD were assessed by angiography as previously described. ${ }^{1}$ During the period 1986-1991 60 patients were identified and followed-up. Because the referral pattern for the unit was predominantly renal in nature rather than hypertension the majority of patients in the intervention and nonintervention groups had impaired renal function. All the patients were offered intervention if it was felt that their renal failure, recurrent left ventricular failure or hypertension could be attributed to the renovascular disease, and if their clinical condition would allow it. Intervention was predominantly in patients with either bilateral disease or disease in a single kidney. Seven patients had procedures with a normal renal artery present on the contra-lateral side for control of blood pressure. In the nonintervention group there were 12 patients with 
bilateral disease or disease in a single kidney where no procedure was performed due to poor operative risk, kidneys too small for salvage or patient preference against intervention. Thus intervention was not undertaken in $32 \%$ of the patients with either bilateral disease or unilateral disease in a single kidney.

The presence of cardiovascular disease was based on a history of myocardial infarct, angina or a positive exercise test. The presence of cerebrovascular disease was diagnosed from a history of previous cerebrovascular accident, transient ischaemic attack or the presence of a carotid bruit. Peripheral vascular disease was defined as a history of claudication or the presence of a femoral bruit. Bilateral disease was defined as the presence of either disease in both arteries or renal artery stenosis in a single kidney. Dialysis-dependent patients at presentation who did not come off dialysis were classified as having stable renal function.

Survival analysis was by Kaplan Meier analysis with significance calculated by log rank analysis. Significant differences between the intervention and nonintervention group were measured by $\chi^{2}$ analysis.

\section{Results}

Table I shows the details of the 60 patients with atherosclerotic renovascular disease. There is an unfortunately high number of patients presenting with undiagnosed ARD on angiotensin converting enzyme inhibitors (ACEI). This is in agreement with Kalra et al. ${ }^{2}$ who found that $4 \%$ of patients with acute renal failure were being treated with an ACEI in the presence of ARD. More widespread use of ACEI may increase this number. The higher incidence of cardiovascular disease in the $Q$ nonintervention group in Table I reflected the fact that this group contained a number of patients unfit for surgical procedures.

In both groups the most common finding was the presence of peripheral vascular disease. This is borne out by the physical signs in these patients as $\overparen{\otimes}$ shown in Table II. The classical association of an abdominal bruit with renal artery stenosis is much ${ }^{\text {क }}$ less common in our series than the presence of a $\vec{O}$ femoral bruit. We feel that this is an important physical sign that should direct attention to the possibility of ARD.

The higher incidence of bilateral disease in the 3 intervention group reflects the urgent need to 9 protect renal function. This is shown by the higher number of dialysis-dependent patients. None of the $\vec{N}$ dialysis-dependent patients came off dialysis in the nonintervention group but three did in the intervention group. The three patients who improved 은 their renal function in the nonintervention group presented with acute exacerbations of their renal $\vec{c}$ disease provoked by either volume depletion or use $\stackrel{\widehat{D}}{\vec{D}}$ of ACEI. When these were corrected their function improved, presumably back to a pre-exacerbatio 8 level. Significantly more patients in the interverte tion group improved their renal function in spite $\dot{\text { sq }}$ this group containing a higher number of dialysisdependent patients than the nonintervention group. One patient with bilateral renal artery stenosis in the intervention group presented with recurrent unprovoked acute left ventricular failure as described by Pickering et al..$^{14}$ This was cured by

Table I Patients' details for the nonintervention and intervention group

\begin{tabular}{lcc}
\hline & Nonintervention & Intervention \\
\hline Total & 28 & 32 \\
Diabetes & $3(10.7)^{*}$ & $5(15.6)^{*}$ \\
ACEI at presentation & $11(39.3)^{*}$ & $12(37.5)^{*}$ \\
Cardiovascular disease & $17(60.7)^{*}$ & $9(28.1)^{*}$ \\
Cerebrovascular disease & $16(57.1)^{*}$ & $10(31.3)^{*}$ \\
Peripheral vascular disease & $27(96.4)^{*}$ & $28(87.5)^{*}$ \\
Bilateral disease & $12(42.9)^{*}$ & $25(78.1)^{*}$ \\
Mean creatinine at presentation & 455 & 356 \\
$\quad(\mu$ mol/l) & & 63.4 \\
Mean age at presentation (years) & 66.9 & $9(28.1)$ \\
Dialysis-dependent at presentation & $4(14.3)$ & $3(33.3)$ \\
Patients no longer requiring & 0 & \\
$\quad$ dialysis, $n$ (\% of dialysis & & $11(34.4) \dagger$ \\
dependent) & & $18(56.3)$ \\
Stable function & $3(10.7)$ & $3(9.4)$ \\
Worse function & $6(21.4)$ &
\end{tabular}

${ }^{*} n$ (\% of group) total. $\uparrow$ Significant $P<0.05$. 
Table II Bruits present in the intervention and nonintervention group

\begin{tabular}{lccc}
\hline Bruits present & $\begin{array}{c}\text { Total } \\
\mathrm{n}(\% \text { all) }\end{array}$ & $\begin{array}{c}\text { Nonintervention } \\
\mathrm{n}(\% \text { non- } \\
\text { intervention) }\end{array}$ & $\begin{array}{c}\text { Intervention } \\
\mathrm{n} \% \\
\text { intervention) }\end{array}$ \\
\hline Carotid & $21(35)$ & $12(43)$ & $9(28)$ \\
Abdominal & $20(33)$ & $9(32)$ & $11(34)$ \\
Femoral & $52(87)$ & $25(89)$ & $27(84)$ \\
\hline
\end{tabular}

bilateral angioplasty but because his renal function was unchanged he is placed in the stable renal function group.

The procedures performed as intervention in the group were angioplasty 13 , second angioplasty 2 , splenorenal anastamosis 2, hepatorenal anastamosis 11 , aortorenal anastamosis 8 and nephrectomy 3. The high number of surgical interventions is a consequence of our group's interest in the new approaches of visceral revascularization especially in patients with total occlusion who are not amenable to angioplasty. The visceral revascularization procedures have been shown to have a lower operative mortality than aortic reconstruction and have a low morbidity. ${ }^{15}$ The aorto-renal procedures were all performed in patients undergoing aortic reconstruction and not for renal artery reconstruction alone. In fact ony one patient having aorto-renal surgery improved renal function after the procedure.

Figure 1 shows the Kaplan Meier curves for survival in each group. The figures are small and no significant difference was reached on log rank analysis. It is, however, clear from the curves that intervention did not increase mortality. It might be expected that the nonintervention group had a worse prognosis as their incidence of known ischaemic heart disease was higher at presentation. Balancing this is the fact that more patients were dialysis dependent at presentation in the intervention group.

\section{Discussion}

Early postmortem studies suggested that renal artery stenosis was much more widespread than diagnosed premortem. ${ }^{16}$ Recent work on patients having angiograms for peripheral vascular disease or cardiovascular disease has demonstrated a high incidence of renal artery stenosis. It has been shown by Choudri et al. ${ }^{17}$ that renal artery stenosis is present in $42 \%$ of patients having angiograms for peripheral vascular disease. The presence of significant atherosclerotic renovascular disease was found by Harding et al. ${ }^{18}$ to be $19 \%$ in a series of

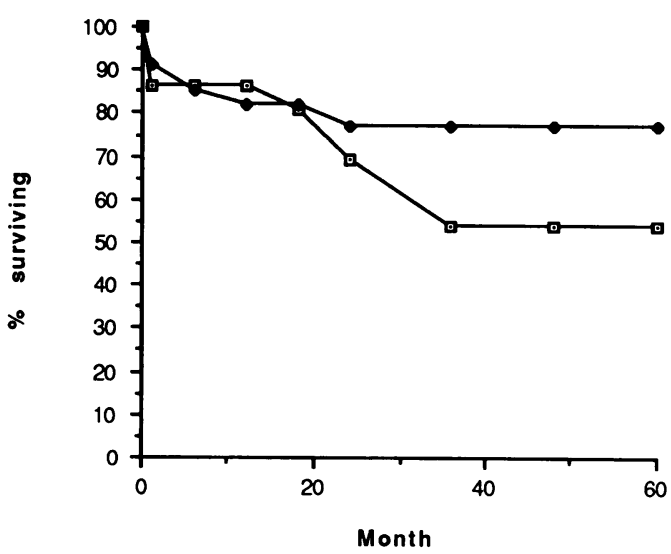

Figure 1 Patient survival with atherosclerotic renovascular disease. Dots within squares = nonintervention; diamonds $=$ intervention.

1,303 patients undergoing coronary angiography. The best discriminant factor for the presence of renal artery disease in these patients was the presence of peripheral vascular disease. The data presented in the present paper re-emphasize the importance of this association. We feel that the presence of femoral bruits is an important indicator to the possible presence of renovascular disease. This is particularly useful in the patient with coronary heart disease where a history of claudication may be lacking. It is possible to define the situations where ARD should be considered on clinical grounds. In the presence of impaired renal function with or without hypertension the following, in order of relative importance, should raise clinical suspicion of the problem: (1) a rise in creatinine on ACEI or positive captopril-enhanced isotopic renogram; (2) the presence of peripheral vascular disease; (3) asymmetrical renal function on isotopic renogram; (4) asymmetric renal size on ultrasound; (5) a history of unprovoked left ventricular failure; (6) coronary artery disease; and (7) cerebrovascular disease.

The absolute criteria for selection for interven- 
tion are unclear although patients must be fit enough to undergo either surgery or angioplasty. Kidney length remains an important factor which correlates with successful revascularization. In early studies it was found that kidneys less than $9.5 \mathrm{~cm}$, as measured on the nephrogram on intravenous urogram or at nephrectomy, did not recover renal function even if revascularized. ${ }^{7}$ It could be that a measure both of renal volume and intrinsic renal damage might be more important. Successful outcomes were achieved by surgery in this present study in kidneys less than $9.5 \mathrm{~cm}$ in length on ultrasound examination. The fact that in the intervention group $9 \%$ of patients had worse renal function after intervention and that six of the nine dialysis-dependent patients did not come off dialysis suggests that we are unable to predict precisely the patients in whom intervention will be successful.

The survival of patients with renovascular disease on dialysis is very poor ${ }^{19}$ even compared with such renal diagnosis as diabetes. In patients with peripheral vascular disease but without renal disease, the survival of patients is decreased in proportion to the severity of the disease. ${ }^{20}$ It is interesting to compare the survival of the patients in the present study with the data published by Criqui et al. who show a 70-75\% 5 year survival for patients with peripheral vascular disease depending on its initial severity. ${ }^{20}$ The nonintervention group has a worse prognosis than this but the intervention group appears to be very similar to the survival for patients with asymptomatic peripheral

\section{References}

1. Scoble, J.E., Maher, E.R., Hamilton, G., Dick, R., Sweny, P. \& Moorhead, J.F. Atherosclerotic renovascular disease causing renal impairment - a case for treatment. Clin Nephrol 1989, 31: 119-122.

2. Kalra, P.S., Mamtora, H., Holmes, A.M. \& Waldek, S. Renovascular disease and renal complications of angiotensinconverting enzyme inhibitor therapy. $Q J$ Med 1990, 282: 1013.

3. Meyrier, A., Buchet, P., Simon, P., Fernet, M., Rainfray, M. \& Callard, P. Atheromatous renal disease. Am J Med, 1988 , 85: $139-146$.

4. Jacobson, H.R. Ischemic renal disease: an overlooked clinical entity? Kidney Int 1988, 34: 729-743.

5. Dean, R.H., Tribble, R.W., Hansen, K.J., O'Neil, E., Craven, T.E. \& Redding, J.F. Evolution of renal insufficiency in ischemic nephropathy. Ann Surg 1991, 213: 446-456.

6. Baird, R.J., Yindt, E.R. \& Firor, W.B. Anuria due to acute occlusion of the artery to a solitary kidney. $N$ Engl $J$ Med 1965, 272: 1012-1014.

7. Lawrie, G.M., Morris, G.C. \& DeBakey, M.E. Long term results of treatment of totally occluded renal artery in forty patients with renovascular hypertension. Surgery 1980, 88: 753-757.

8. Madias, N.E., Kwon, O.J. \& Millan, V.G. Percutaneous transluminal angioplasty: a potentially effective treatment for preservation of renal function. Arch Intern Med 1982, 142: 693-697. vascular disease in the San Diego study. A difference from the San Diego study is the very high initial mortality in both groups. Our patients were presenting predominantly due to renal impairment and many were seriously ill at presentation. It could be that a prior diagnosis of their renovascular disease might have lessened this initial high mortality.

The data in this paper document the clinical features of patients presenting to this unit over a 6 year period with atherosclerotic renovascular disease. It can be seen that intervention can improve renal function in about one third of patients as measured by a fall in plasma creatinine and that this figure would be higher if such symptoms as unprovoked left ventricular failure were included. As measured by release from dialysis then intervention can be successful. It is, however, apparent that intervention is not possible for many reasons in almost a half of the patients and that selection of patients in whom improvement will occur is not clear. In terms of survival it is difficult to decide in a non-randomized population whether intervention has produced any change. What can be said from these data though is that intervention does not increase mortality when compared to either a similar published group with peripheral vascular disease or patients in whom intervention does not 8 occur. In selected patients revascularization is an important therapeutic manoeuvre in patients witho atherosclerotic renovascular disease and renal? impairment.

9. Kaylor, W.M., Novick, A.C., Ziegelbaum, M. \& Vidt, D.G. Reversal of end stage renal failure with surgical revascularization in patients with atherosclerotic renal artery occlusion. $J$ Urol 1989, 141: 486-488.

10. Bengtsson, U., Bergentz, S.E. \& Norback, B. Surgical treatment of renal artery stenosis with impending uremia. Clin Nephrol 1974, 2: 222-229.

11. Morgan, T., Wilson, M., Johnston, W., Clunie, G.J. \& Gordon, R. Restoration of renal function by arterial surgery. Lancet 1974, 1: 653-656.

12. Sheil, A.G.R., May, J., Stokes, G.S., Johnson, J.R., Tiller, D.J. \& Stewart, J.H. Reversal of renal failure by revascularization of kidneys with thrombosed renal arteries. Lancet 1973, 2: 865-866.

13. Ying, C.Y., Tifft, C.P., Garvas, H. \& Chobanian, A.V. Renal revascularization in the azotemic hypertensive patient resistant to therapy. N Engl J Med 1984, 11: 1070-1075.

14. Pickering, T.G., Herman, L., Devereux, R.B. et al. Recurrent pulmonary oedema in hypertension due to bilateral renal artery stenosis: treatment by angioplasty of surgical intervention. Lancet 1988, 2: 551-552.

15. Moncure, A.C., Brewster, D.C., Darling, R.C., Atnip, R.G., Newton, W.D. \& Abbott, W.M. Use of the splenic and hepatic arteries for renal revascularization. J Vasc Surg 1986, 3: 196-203.

16. Schwartz, C.J. \& White, T.A. Stenosis of renal artery: an unselected necropsy study. Br Med J 1964, 2: 1415-1421. 
17. Choudri, A.H., Cleland, J.G.F., Rowlands, P.C., Tran, T.L., McCarthy, M. \& Al-Kutoubi, M.A. Unsuspected renal artery stenosis in peripheral vascular disease. $\mathrm{Br}$ Med J 1990, 301: 1197-1198.

18. Harding, M.B., Harrison, J.K., Phillips, H.R., Schwab, S.J., Himmelstein, S.I. \& Bashmae, T.M. Renal artery stenosis: incidence and associated risk factors in 1,303 patients undergoing routine cardiac catheterization. J Am Soc Nephrol 1990, 1: 334 .
19. Mailloux, L.U., Bellucci, A.G., Mossey, R.T. et al. Predictors of survival in patients undergoing dialysis. Am J Med 1988, 84: $855-862$.

20. Criqui, M.H., Langer, R.D., Fronek, A. et al. Mortality over a period of 10 years in patients with peripheral arterial disease. $N$ Engl J Med 1992, 326: 381-386. 